\title{
Article Title: Global Citizens or Global Workers? Comparing university programmes for global citizenship education in Japan and the UK
}

\author{
Authors: Christopher D. Hammond* (corresponding author) and Dr Avril Keating \\ Department of Education, Practice and Society, UCL Institute of Education, University College London \\ Published online in Compare in September 2017.
}

\section{PRE-PROOF VERSION.}

For final version, see http://dx.doi.org/10.1080/03057925.2017.1369393.

\begin{abstract}
In recent years, higher education (HE) institutions have increasingly been articulating the need to produce global citizens capable of meeting the social, political and economic demands of the 21 st Century. The implementation of global citizenship programmes at the university level has been taking place against a backdrop of growing internationalization and marketization in higher education, leading some to conclude that universities are cultivating global workers rather than global citizens. This small-scale exploratory study aimed to explore these claims through the comparison of GCE programmes in two contrasting contexts - the UK and Japan. Through a combination of quantitative and qualitative approaches to content analysis, our findings suggest that the universities in both the UK and Japanese contexts demonstrate examples of adaptation and localization of GCE to fit with institutional commitments, and both universities have significant elements of employability agendas infused into their programmes. The Japanese case tends to emphasise the development of 'global human resources', as well as the importance Japanese national identity, which aligns with critiques of Japan's typically ethnocentric and nationalistic approach to internationalization. The UK case, by contrast, refrains from any mention of the UK, and focuses instead on global and local issues as well as demonstrating a marketing-oriented approach emphasizing university branding and promotion. We argue that while different in many respects, the two programmes both demonstrate an adaptation of GCE to fit within broader internationalization strategies aimed at maximizing global competitiveness and an alignment with the neoliberal trends shaping the global higher education sector.
\end{abstract}

\section{Key words}

Global citizenship; higher education; internationalization; comparative higher education; Japan; UK

\section{Introduction}

Global citizenship (GC) has emerged in recent years as a policy agenda of organisations operating at levels ranging from the local to the supra-national, and can increasingly be found shaping the programming and 
curricula of educational institutions around the world. Higher education institutions are no exception, with many universities articulating the need to produce global citizens capable of meeting the social, political and economic demands of the 21st Century. Global Citizenship Education (GCE) programming has appeared in the higher education (HE) sector in the context of globalization, internationalization, and dramatic shifts in the management, organisation and perceived role of universities. According to Marginson (2014) these shifts are in large part due to the expanding influence of neoliberal ideologies and the subsequent reshaping of universities in the image of private corporations. This increasingly marketized HE environment has, in turn, led to the re-conceptualization of students as customers, leading some to argue that student satisfaction and employability rates have superseded the traditional goals of HE teaching and learning (i.e. the production of informed, well-rounded and critically engaged citizens) (Giroux, 2002). The question then arises, in today's era of neoliberal global higher education, are universities actually aiming to produce global citizens or simply global workers?

Despite these concerns, there is relatively little comparative and empirical research on how universities are conceptualizing global citizenship in their policies and practices; to date, much of the empirical research on GC has focused on school-level initiatives. To begin to address this imbalance, this paper presents a comparative analysis of GCE programmes at two universities in two contrasting contexts - the UK and Japan. By focusing on two case studies from contrasting contexts, we will examine the following questions:

1. How is education for global citizenship being conceptualized in university policies and programmes?

2. How is this concept being reframed in different national and institutional contexts?

3. To what extent are the GCE programmes focused on producing global workers rather than global citizens?

To address these questions, we analysed GCE policy and programming documents for each case that were available in the public domain. These were analysed using a primarily qualitative thematic approach to content analysis (supported by a quantitative keyword search) and interpreted using a conceptual framework to identify and distinguish characteristics of global citizens and global workers. The findings from each case were also analysed comparatively to investigate the ways that GCE has been reframed in the two contrasting contexts. While these national and institutional contexts do vary in a number of ways, there are also noteworthy worldwide trends in HE indicating the sector is converging towards a global, marketized model. This global higher education context in which the two countries and cases find themselves is introduced in the following section. 


\section{The globalization and internationalization of higher education}

Worldwide, governments and universities are experiencing pressure to internationalize their curricula and student bodies and to improve their global presence and competitiveness. These pressures have been prompted by transformations in global trading and labour markets, the impact of technological development on skill requirements, as well as by the rhetoric about the transformative power of globalization (see (Brooks \& Waters, 2013; Brown, Lauder, \& Ashton, 2011). These trends have then been further amplified by the prevalence of global rankings of universities, which place pressure on universities to respond to increased global competition in areas such as research, innovation, and international standing (Marginson, 2011; Marginson \& van der Wende, 2007). In response to these developments, governments and universities have developed a range of strategies and innovations, including developing closer cooperation with industry (Rhoads \& Szelenyi, 2011), investing in the development of world-class universities and research hubs (Mok, 2007), and recruiting increased numbers of international students to the HEI in the 'home' country (see Huang, 2007).

As part of this trend, many internationalised universities are increasingly discussing how their pedagogy and curricula can equip their students to become global graduates that have the competences that are required in the globalized graduate employment market (Brooks \& Waters, 2013). As Diamond et al (2011) point out, "multinational employers, and increasingly employers of all kinds, require their workforce to work readily and confidently across worldwide operations, using a global outlook to consider new opportunities and challenges" (ibid, p. 5). Some of the key competencies being sought by global employers include: "a global mind-set and cultural agility; communicating effectively in a global environment; the ability to work collaboratively in multi-cultural teams; managing complex interpersonal relationships; adaptability, drive and resilience; and knowledge of global affairs (Diamond, et al, 2008). Proficiency in English and/ or a second language is also increasingly in demand.

\section{Internationalisation through Global Citizenship Education}

Many universities are responding to this demand for global workers by offering new programmes and services aimed at enhancing the global employability of their graduates. But alongside policy discussions about global graduates, there have also been an increasing number of policies and programmes focusing on global citizenship. These policies and programmes are varied, but often include elements such as taught courses, study abroad experiences, and 'capping' projects that culminate in the awarding of Global Citizenship certificates (see Jorgenson \& Shultz, 2012). The proliferation of study abroad and international service learning programmes has garnered particular attention (Lewin, 2009), but there are also a number of GCE programmes that take place partly or completely at home on university campuses. A number of 
universities have also revised their mission statements to include reference to their commitment to educate for global citizenship.

This interest in introducing global citizenship education at university is part of a wider debate about the meaning and practice of 'global citizenship' (Dower, 2003; Rhoads \& Szelenyi, 2011; Schattle, 2009). A common thread in these debates is that the relationship between individuals, governments and political institutions is evolving so that citizens' rights, identities, and sites of civic engagement can be derived from global, national and local spaces, rather than exclusively from nation-state institutions (as has historically been the case in the modern era) (Keating, 2014). Yet while there is common agreement that citizenship is evolving, what it is (or should be) evolving into remains subject to debate; as Oxley and Morris (2013) point out, global citizenship has been conceptualised in a wide variety of ways, some of which focus on political, cultural or economic dimensions, while others focus on spiritual, environmental or moral aspects.

A diversity of approaches is equally apparent when it comes to theory, policy and practice in education for global citizenship (GCE). However, Oxfam's Guide for Schools (2006, and updated in 2015) has become an influential document for GCE practitioners, and its impact extends beyond the British schools that it was originally developed for (Marshall, 2009, p. 250). According to this Guide,

Education for global citizenship is a framework to equip learners for critical and active engagement with the challenges and opportunities of life in a fast-changing and interdependent world. It is transformative, developing the knowledge and understanding, skills, values and attitudes that learners need both to participate fully in a globalised society and economy, and to secure a more just, secure and sustainable world than the one they have inherited (Oxfam, 2015, p. 5).

While this definition seems abstract, the guide goes on to provide a more detailed description of (or proscription for) what GCE should entail; this includes: knowledge of topics such as human rights, diversity and globalization; skills such as critical thinking, co-operation and conflict resolution; and values and attitudes such as commitment to social justice and concern for the environment (see also Table 1 below).

The Oxfam GCE Guide for Schools was designed for learners aged 3 to 19, rather than universities, and at the higher education level, there does not appear to be a similarly comprehensive framework. In the United States, the Association of American Colleges and Universities (AAC\&U) funded ten US universities to create GCE programmes, and stipulated that these programmes should aim to: generate new knowledge about global studies; enhance civic engagement and social responsibility; promote a deeper knowledge and debate about the practice of democracy; and cultivate intercultural competencies with faculty and students (Jorgenson and Shultz, 2012: p. 8). However, this unified approach to GCE at the HE level is more the exception than the norm; many HEIs end up implementing GCE policies of their own design. 


\section{Global Citizens or Global Workers?}

Both the internationalisation of universities and the development of GCE have attracted a great deal of debate and criticism. The first set of critiques raise questions about whether universities can still promote democratic and/ or critical citizenship in a context in which internationalisation is so closely tied to marketization and commercialisation. This argument stems from concerns about the underlying driver of internationalisation (neoliberalism) and the impact it is having on university aims and policies. According to Marginson (2014), "for more than two decades now, the primary ideas about government and social organisation in higher education, and the main propositions for reform, have been drawn from neoliberalism" (Marginson, 2014, p. 17). Originating in the UK and the US, neoliberal policies have spread worldwide through processes of globalization (ibid.). Briefly defined, neoliberalism "denotes new forms of political-economic governance premised on the extension of market relationships", is "associated with the preference for a minimalist state" and advocates for deregulation and privatization (Larner, 2000, p. 5). One consequence of the influence of neoliberalism has been the remodelling of universities in the image of private corporations. Universities are thus increasingly seen by governments as "self-interested firms in competition with other firms like them", which "obscures their contribution to the collective interest" (Marginson, 2014, p. 19). Terms such as 'commodification' (Naidoo \& Jamieson, 2005), 'commercialization' (Altbach \& Knight, 2007), and 'marketization' (Lynch, 2006) have thus become common descriptors for the processes shaping universities worldwide.

These trends have had a knock-on effect on academic research. Rhoads \& Szelényi (2011) note that higher education has become much more responsive to the research needs of private industry, and much more reliant on the income streams accrued from doing so (a phenomenon which they describe as a form of academic capitalism). As funding for research has increasingly come from for-profit organisations, Rhoads and Szelényi argue that this model is incentivizing some researchers to ignore important social problems in favour of projects that will generate the most revenue. More broadly, it has been suggested that this trend is also leading universities to prioritise disciplines that are capable of generating substantial funding from private industry (such as the natural and applied sciences) and to deprioritise the social sciences and humanities disciplines.

Amidst these shifting priorities, some scholars lament that the university is losing its ability to foster the development of critical, socially engaged citizens and is leading to an academic culture defined by "market driven notions of individualism, competition and consumption"(Giroux, 2002, p. 426). Giroux claims this poses a significant threat to students at universities, as in his view, higher education: 
...is one of the few public spaces left where students can learn the power of questioning authority, recover the ideals of engaged citizenship, reaffirm the importance of the public good, and expand their capacities to make a difference (ibid., p. 450).

Indeed, such is the power of these corporate interests and neoliberal ideologies, that only "a profoundly committed sense of collective resistance" will safeguard the civic role of universities (ibid, p. 457). Whether or not this collective resistance materialises, neoliberalism and academic capitalism are likely to continue influencing the policies and practices of higher education for the foreseeable future.

\section{Tensions in global citizenship education}

A second set of criticisms focus their attention more specifically on the GCE programmes that have been established. The development of global citizens through study abroad and international service learning (i.e. international volunteering) has come in for particular criticism, with some noting that as these opportunities have expanded and become more widely accessible, they have also become commodified, shifting from authentic intercultural experiences to little more than 'fun' and 'exotic' consumer products. Others have argued that the growth of programmes for university students in developing countries represent a form of colonialist 'poverty tourism' that "reinforces stereotypes of themselves and others" (Lewin, 2009: p. Xv). More broadly, questions have been raised as to whether GCE programmes are more concerned with cultivating global workers rather than global citizens. Indeed, if we compare the GCE frameworks proposed by the likes of Oxfam (2015) and the global graduate worker debates (such as CFE, 2011), we can see that there is a lot of overlap in the type of characteristics that are being advocated. As Table 1 illustrates, Global Citizens and Global workers are deemed to need skills such as critical thinking, dispositions such as leadership, and values such as respect for diversity.

However, there are also notable differences, with Global Citizen frameworks placing more emphasis on civic, social justice and environmental issues, while the characteristics of the Global Worker relate more to their economic function. Yet even the Oxfam framework has been influenced by the economic/employability agenda; while the 2006 framework makes no reference to economic, the revised Guide (2015) now states that 'Education for global citizenship is a framework to equip learners...to participate fully in a globalised society and economy...' (Oxfam, 2015, p. 5; emphasis added).

\section{TABLE 1: Comparing the characteristics of Global Citizens and Global Workers}

\begin{tabular}{|c|c|c|}
\hline $\begin{array}{c}\text { Characteristics unique to } \\
\text { Global Citizens }\end{array}$ & $\begin{array}{c}\text { Characteristics of both Global Citizens } \\
\text { and Global Workers }\end{array}$ & $\begin{array}{c}\text { Characteristics unique to } \\
\text { Global Workers }\end{array}$ \\
\hline
\end{tabular}




\begin{tabular}{|c|c|c|}
\hline 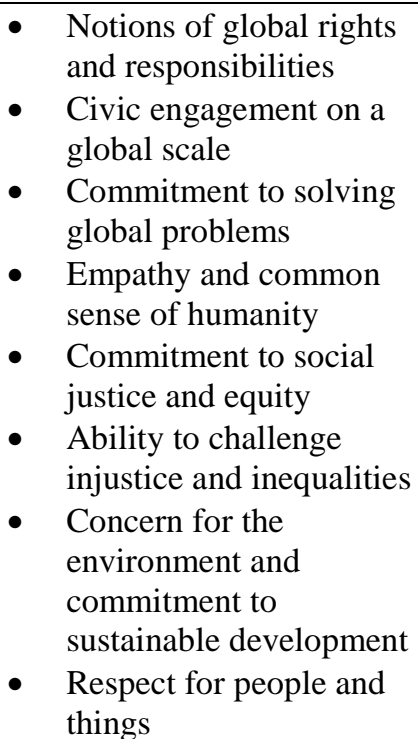 & $\begin{array}{l}\text { - } \text { Critical thinking skills } \\
\text { - Ability to argue effectively } \\
\text { - A high degree of drive and resilience } \\
\text { - Self-awareness } \\
\text { - Co-operation and conflict resolution } \\
\text { - Collaboration with cross-cultural } \\
\text { - } \quad \text { Awareness of global issues } \\
\text { - Value and respect for diversity } \\
\text { - Leadership } \\
\text { - Economic engagement on a global } \\
\text { - Scale } \\
\text { - Social engagement on a global scale } \\
\text { - } \text { perspectives } \\
\text { Adaptability and flexibility }\end{array}$ & $\begin{array}{ll}\text { - } & \text { Global competitiveness } \\
\text { - } & \text { Ability to form } \\
\text { professional, global } \\
\text { networks } \\
\text { - } \\
\text { The ability to negotiate } \\
\text { and influence clients } \\
\text { from various } \\
\text { backgrounds } \\
\text { - } \\
\text { Global commercial } \\
\text { awareness } \\
\text { - Second language ability } \\
\text { Knowledge of foreign } \\
\text { economies and own } \\
\text { industry area overseas }\end{array}$ \\
\hline
\end{tabular}

Adapted from Oxfam's Curriculum for Global Citizenship (2015) and the CFE Global Graduate report (2011)

\section{Gaps in the literature and relevance of the study}

These critiques raise the question: In today's marketized HE environment, to what degree is education for global citizenship focused on the production of global workers? Highlighting the ways in which GCE programmes may in fact be thinly guised attempts at developing employable, globally competitive graduates would lend support to claims of a co-optation of the traditional 'public space' role of HE by a neoliberal agenda. To date, much of the empirical research on GCE has focused on school-level policies (see Marshall, 2009, p. 255; Schweisfurth, 2006). Research on GCE in higher education has tended to be more normative, with a range of scholars offering ideas of what global citizenship in HE should be (for examples, see Nussbaum, 2002; George-Jackson, 2010), while others critique the neoliberal structural conditions of higher education that impose obstacles to the implementation of preferred forms of GCE (Haigh, 2008). A key aim of this article, therefore, is to examine GCE programmes empirically, and to investigate how universities are conceptualising global citizenship and the extent to which these conceptions intersect and interact with the global worker debates.

A further gap in the literature concerns debates about the West-centric theoretical underpinnings of global citizenship, and the notable deficiency of comparative studies investigating the ways GCE programmes are implemented in practice in Western and non-Western contexts. Previous research has shown that global and European citizenship education policies are re-framed in order to reflect nation-state priorities and national conceptions of citizenship (Keating, 2014; Keating et al., 2009). However, much of the comparative analysis on the GCE programmes in universities has focused on Western countries and where English is the dominant language (see for example Jorgenson \& Shultz, 2012; Mitchell, 2003; Pashby, 
2011). Research limited by this linguistic constraint may skew perceptions of global citizenship as a policy dominated by the West, leading to biased justifications of post-colonial critiques of GCE. Research into GCE policy in Japan also exists (examples include Fujikane, 2003; McCullough, 2008; Willis, 2002; Yonezawa, 2014) but tends to lack any form of comparative analysis that might shed light on the way GCE is reframed and localized in different national and institutional contexts. Our study comparing the contrasting contexts of the UK and Japan will thus provide a novel contribution to the literature.

\section{Data and methods}

For this small-scale exploratory study, a case-study approach centring on document analysis was adopted. The research questions were addressed through the collection and analysis of documents using quantitative and qualitative (thematic) content analysis. To compare higher education GCE programming in Japan and the UK, one university was selected from each country. The individual universities selected were chosen based on the degree to which the institutions demonstrate the types of programmes that are relevant to this study and provide a suitable means for comparison across the two countries. The universities that were selected as cases were Kwansei Gakuin University (KGU) in Japan and University College London (UCL) in the UK, both of which have articulated GCE policies and programming (and which are described below).

The primary source for documents was the webpages of the selected universities, which were accessed during the months of March and April, 2016. To determine the type and number documents for this study, a preliminary search for policy texts and marketing messages that mentioned 'global' or 'world' citizens, 'global citizenship', and information on GCE programmes was conducted, and research articles and other documents that were not representative of approved university policy were excluded. Two categories of documents were selected as a sub-sample for the data collection phase. They were (a) University president or vice-chancellor messages on global citizenship, and (b) GCE programme webpages. A full list of the documents analysed here can be found in Appendix A. Scott's (1990) criteria of authenticity, credibility and representativeness were applied to all documents to ensure as much as possible their suitability for the study.

The analysis was conducted in four stages, and involved both quantitate and qualitative methods of analysis. First, we used Table 1 to derive a series of deductive codes for the quantitative content analysis. As part of this coding process, we identified key words (e.g. volunteering) and possible synonyms (e.g. voluntary work) that we expected could appear in the texts. Second, we then piloted this coding frame, using a sample of documents from each case. This led us to identify new salient terms, thus ensuring that our final coding framework included not just keywords that feature in Table 1, but also synonyms and GCE-related concepts that we had not anticipated. Once we had established our deductive coding frame, we then conducted a 
quantitative content analysis of keywords and associated words in the final sample of documents. These keyword searches were conducted in English in the UCL case, and Japanese in the case of KGU. This quantitative approach helped us (a) to obtain a preliminary understanding of the different dimensions of GC featured (or not featured) in the programme documents; (b) to gain insight into their relative importance in the policy corpus; (c) to triangulate the findings from the qualitative analysis that was conducted in the qualitative element of the analysis. For this qualitative stage, we adopted a thematic analysis approach (add reference). This enabled us to examine and compare how the key GC themes were conceptualised and framed in the documents. The results of this analysis are the main focus of the findings discussed below, and the findings from the quantitative analysis provide supportive and contextual information.

The discussion of global citizenship in the previous section highlights that while global citizens and global workers may share common traits there is a clear distinction between the varied interpretations of what it means to be a global citizen and the characteristics of a global worker outlined above. The primary means by which to distinguish between the two for the purposes of this study will be defined as follows: a global citizen is an individual who assumes and exercises a set of rights and responsibilities through their role as a civic, economic and social actor in a globalized society, while a global worker is an individual with the skills, knowledge, character traits and experiences required to be productive and successful in the globalized workplace. The framework used to aid in distinguishing between the two can be found in Table 1 .

A challenge for determining the degree to which GCE programmes emphasize the development of global workers is the substantial overlap in characteristics required of both global citizens and global workers noted in Table 1. This challenge was addressed by focusing on keywords that highlight characteristics unique to either of the two distinct categories. A further challenge to analysis comes from the limitations imposed by the inherent bias in the GC/GW framework above, due to the fact that the criteria for identifying both global citizens and global workers were developed by NGOs advocating from particular normative perspectives. Arguably any academic or advocacy-based theory of these constructs will be underpinned by normative assumptions. In addition to these inherent biases, it is also important to recognize that these normative assumptions and thus the framework itself are decidedly 'Western', and thus the non-Western case of a Japanese university is being viewed and analysed through a Western lens. We argue this does not hinder the analysis, however, because part of our goal here is to examine the extent to which Western policy discourses are influencing non-Western contexts. A final consideration is that the KGU documents surveyed contained approximately half of the total text the UCL documents did. Thus, it is conceivable to imagine that given texts with equal word counts, the frequency of keywords in the KGU case (highlighted in Table 2 below) would be considerably higher. For this reason, we report both the number of references and the percentages of text devoted to each keyword category to highlight the relative importance of the 
concepts with the document sample that we identified. Taking these limitations of the framework and other issues into consideration, the following sections present the findings of the study in the context of the research questions.

\section{Conceptualizations of education for global citizenship in university policies and programmes}

Analysis of the two cases highlighted the variation in possible approaches to delivering GCE programming. The most immediately obvious differences with these particular cases were (a) programme duration and (b) level of access to students. UCL's GCE programme lasted only two-weeks but was open to all students at the university while the KGU offering was ingrained into course curricula and spanned the entire course of students' undergraduate degrees but was available only to a select number of students. A range of other differences became apparent through analysis of the documents and will be introduced and discussed below.

\section{The Structure of GCE Programmes}

The UK case, UCL, has declared as one of its primary aims to "prepare [its] students for a globalised world through studies of cultural diversity, global citizenship and leadership..." (UCL, webpage R.). As part of this remit, all students are offered the opportunity to participate in the Global Citizen Programme (GCP), a two-week programme delivered through taught lectures and active project work, with a view to giving students "the chance to put [their] studies in a global context, learn new skills and see the world differently..." (UCL webpage A, n.d.). Participants can choose to focus on particular topics that are linked to the university's 'Grand Challenges Strategy' which aims to address a number of complex global problems in areas (such as global health, sustainable cities, and human wellbeing) through crossdisciplinary research and innovation. Alternatively, students can follow one of a number of 'Pathways' entitled 'Enterprise', 'Employability', 'Voluntary Sector' and 'Active Citizenship'. The GCP is primarily aimed at first and second-year undergraduates, although postgraduate students can participate in the Pathway options. UCL thus takes a broad and varied approach to its GCE programme, and has notably incorporated a career-oriented strategy with the inclusion of its 'Enterprise' and 'Employability' pathways.

While UCL has, to date, opted for an intensive two-week option which takes place in the summer, Japan's KGU has adopted a different approach to GCE in terms of content and programme structure. KGU's programme requires a few years to complete and students are required to complete up to 40 credit hours (one module counts for between 1 and 3 credits) as well as a period of education abroad. The programme is divided into the areas of 'Language Education', 'Global Studies', 'Life Design' and 'Interdisciplinary Subjects' (KGU webpage K, n.d.). A range of modules are on offer, including 'Introduction to Multicultural Studies', 'Introduction to International Relations', and 'Global Career Design'. The strand of the 
programme entitled 'Life Design' has an employability focus, and includes careers seminars and modules on internships and 'work/life balance'. The largest selection of offerings is second (or other) language courses. Interestingly, the only languages on offer are French, German and English, with English making up the lion's share of available modules. The languages of Japan's neighbours such as China and Korea are notably absent. While East Asian and other languages are offered at the university, this decidedly Eurocentric approach to language education in the GCE programme is telling, and aligns with critiques of Japan's approach to internationalisation which has tended to ignore its regional neighbours and its own multi-cultural makeup in favour of engaging with the English-speaking West (Tsuneyoshi, 2011).

KGU is one of 37 Japanese universities selected for funding from the Ministry of Education for the government's ‘Top Global University' and 'Promotion of Global Human Resources' projects. The 'Top Global' project aims to "provide prioritized support for the world-class" and "innovative universities that lead the internationalization of Japanese society” (MEXT, 2014). The 'Global Human Resources' project has the objective to "foster human resources who can positively meet the challenges and succeed in the global field, as the basis for improving Japan's global competitiveness and enhancing the ties between nations" (MEXT, n.d.). KGU has thus incorporated these government initiatives into its programme design, calling its GCE progamme the 'World Citizen X Global Human Resources' programme. In the title alone, then, it becomes apparent that there is a clear message concerning the production of global workers alongside the cultivation of 'world citizens', and the documents that were analysed supported this. The employability agenda found in both cases will be discussed in more detail below.

\section{Definitions of Global Citizenship and emergent themes from the document analyses}

The differences in the two universities approaches to GCE were immediately apparent when reading the ways each chose to define the characteristics of a 'global citizen'. UCL defined global citizens as follows:

“Global citizenship is UCL's initiative to build students who:

- look beyond their individual and local interests and see the complexity of an interconnected world

- understand the nature of the challenges that face that world

- are aware of their social, ethical and political responsibilities

- are ready to display leadership and work together to change the world for the better

- $\quad$ are able to solve problems through innovation and entrepreneurship

- prosper in a global jobs market that values the skills UCL provides" (UCL webpage S, n.d.)

Meanwhile, KGU's president describes how the University's 'world citizens' will demonstrate the following characteristics:

- Having the motivation to continuously work on improving foreign language ability and communication skills

- Have the motivation to learn and have the power of independent thought and action 
- To be unafraid and have a spirit of perseverance in the face of challenges; summarizing and prioritizing tasks to solve problems

- To 're-evaluate' Japan, have an interest in foreign cultures, develop intercultural understanding, as well as a Japanese identity.

- An interest in trends in society shaped by 'public-spiritedness', an ethical view and a commitment to social justice. (translated from KGU webpage A, n.d)

These two definitions epitomise some of the key differences and similarities in approaches to GCE in the different cases. On the one hand, both seem to stress social justice, ethical actions, and addressing the challenges facing humanity. On the other hand, KGU places more emphasis on language skills acquisition and independent action, while UCL emphasises the need to work together with others. This may reflect the differing needs of a community-based society (Japan) versus a more individualist society (UK). It is also striking that UCL makes its connection to the employability agenda far more explicit through its references to innovation, entrepreneurship, and the global jobs market.

Further differences emerged in the policy documents that were associated with the GCE programmes in the respective cases. These themes included: (1) a variation in attention to particular global issues; (2) an emphasis (or lack thereof) on education abroad; (3) varying focus on notions of 'global', 'international', 'national', and 'local'; (4) levels of alignment of the GCE programme with institutional and national strategy; (5) skills development; and (6) employability. To illustrate the differences in each case, Table 2 sets out the frequency of keywords (and associated words) related to these themes.

TABLE 2: Emergent Themes and Frequency of Related Keywords in GCE Programmes

\begin{tabular}{|l|c|c|}
\hline \multicolumn{2}{|l|}{ UCL } & \multicolumn{1}{|c|}{ KGU } \\
\hline Emergent themes: Focus on Education Abroad, Language and Global Issues & \\
\hline Keyword categories & & $50(1.06 \%)$ \\
\hline Study abroad & $8(.08 \%)$ & $31(.65 \%)$ \\
\hline Volunteering & $19(.18 \%)$ & $18(.38 \%)$ \\
\hline Foreign language education & & \\
\hline Emphasis on global issues & $31(.3 \%)$ & $38(.80 \%)$ \\
$\bullet \quad$ Social & $31(.3 \%)$ & $6(.12 \%)$ \\
$\bullet \quad$ Environmental & $15(.15 \%)$ & $2(.04 \%)$ \\
$\bullet \quad$ Political & $4(.04 \%)$ & $17(.36 \%)$ \\
• Eultural & $6(.06 \%)$ & $3(.06 \%)$ \\
\hline Emergent themes: Focus on Global, International, National, and Local contexts & \\
\hline Keyword categories & & \\
\hline Global & $161(1.6 \%)$ & $96(2.04 \%)$ \\
\hline International & $10(.1 \%)$ & $66(1.4 \%)$ \\
\hline Nation/country & $6(.06 \%)$ & $21(.44 \%)$ \\
UK (Great Britain, England); Japan & 0 & $26(.55 \%)$ \\
\hline Local & $28(.28 \%)$ & $3(.06 \%)$ \\
\hline
\end{tabular}




\begin{tabular}{|c|c|c|}
\hline $\begin{array}{l}\text { Emergent themes: Alignment with Institutional and National } \\
\text { Strategy }\end{array}$ & & \\
\hline \multicolumn{3}{|l|}{ Keyword categories } \\
\hline Reference to Institution & $121(1.2 \%)$ & $18(.38 \%)$ \\
\hline Reference to national strategy/policy & 0 & $8(.17 \%)$ \\
\hline Reference to Institutional Strategies, Values or Motto & $20(.2 \%)$ & $9(.19 \%)$ \\
\hline \multicolumn{3}{|l|}{ Emergent themes: Employability agenda and Skills Development } \\
\hline \multicolumn{3}{|l|}{ Keyword categories } \\
\hline $\begin{array}{l}\text { Inclusion of terms related specifically to employability agenda (e.g. } \\
\text { networking, career, professional edge) }\end{array}$ & $68(.7 \%)$ & $26(.55 \%)$ \\
\hline Emphasis on Skills development & $54(.53 \%)$ & $18(.38 \%)$ \\
\hline Total number of documents consulted & 19 & 10 \\
\hline Word count & 10,069 & 4700 \\
\hline
\end{tabular}

A major difference between the two programmes was the emphasis, or lack thereof, on studying abroad. At KGU, studying or volunteering abroad and getting an international experience is a major aspect of the GCE programme. At UCL study abroad is not mentioned at all in the GCE programme pages, and UCL's GCE volunteering opportunities take place within the local environs. The focus on local teaching and volunteering activities is perhaps unsurprising given short duration of UCL's GCE programme. However, it is notable that the GCE programme pages do not discuss or link to other UCL webpages that might facilitate longer engagement and study or volunteering abroad opportunities.

Foreign language study, especially English, was heavily emphasised in the KGU case. English language study unsurprisingly is not a concern at UCL, as students who are enrolled at the university are already expected to have demonstrated English language proficiency through the IELTS or other examinations. However, the study of other foreign languages is generally not emphasised in the UCL case, with the exception being one Pathway of the GCE programme focusing on the cultures and societies of the Danube River that offers language 'taster sessions'. As mentioned above, KGUs emphasis on English and other European languages while omitting opportunities to study Mandarin, Korean or other regional Asian languages is revealing of an underlying strategy and orientation toward internationalisation. Arguably, as English is now the linga franca of global scientific research and multinational business, it is imperative for graduates who wish to compete in the global knowledge economy to have communicative competency in English. Furthermore, when communicating across linguistic boundaries, the default language of communication is often English (Graddol, 2000). This emphasis on English language education at KGU coincides with approaches to HE internationalisation found in many non-English speaking developed nations (Huang, 2007). In order to compete in the global higher education marketplace and leverage their positions with respect to the top-ranked HEIs in the English-speaking world, many universities have begun offering courses in English to increase the inward mobility of foreign students and prepare their home students for global careers. These factors explain to some degree the emphasis put on the promotion of 
English language programming at $\mathrm{KGU}$, as well as the importance placed on study abroad to gain international experience and foreign language skills. However, this emphasis on English-language proficiency also suggests that fostering cross-cultural awareness and communicative competence at the regional-level (through the study of East Asian languages) is not a key element of the KGU conceptualisation of 'world citizens'.

Differences in the focus on particular issues surrounding discourses of GC were also apparent. Both institutions frequently referenced 'social' issues that highlighted the interconnections of individuals and societies. UCL also focused on environmental and political issues with relative frequency with $31(.3 \%)$ and $15(.15 \%)$ mentions, respectively, to KGU's $6(.12 \%)$ and $2(.04 \%)$ (see Table 2). Most of these conceptions of GC were alluded to in reference to the global problems facing humanity and UCL's mission to address these problems through world-class research and cross-disciplinary collaboration. KGU, by contrast, focused less on these areas and more on addressing 'culture', with 17 mentions (.36\%) to UCL's $4(.04 \%)$, often in the context of understanding and learning to cooperate with people from other cultures through the development of teamwork, communication skills, and multicultural understanding.

The messages of the universities' presidents also highlighted some notable differences in the way GC was conceived. The KGU president tended to place more emphasis on language learning and developing an understanding of 'foreign' cultures, and this also included a statement of the importance of developing a 'Japanese' identity (KGU webpage A, n.d.). By contrast, the UCL Provost's message had more of an emphasis on diversity, interconnectedness, and the multicultural nature of being a student at UCL, describing it as “'London's Global University” with fellow students from 150 countries as well as 100 staff nationalities" (Arthur, 2015) (emphases added).

\section{Reframing GC in different national and institutional contexts}

Comparative analysis of the selected documents highlighted a number of examples of how GCE is reframed to fit national and institutional contexts. An emergent theme in both cases was the varying emphases placed on notions of the global, international, national and local. To clarify, the term 'local' does not include references to the institutions themselves, but to the local communities in which the universities reside. Analysis revealed that UCL focused on the 'global' and 'local' in its GCE documents, and made no references to the United Kingdom (or Great Britain, or England) whatsoever. As 'local' for UCL is the cosmopolitan city of London, these references highlighted the opportunities for gaining cross-cultural experiences both inside and outside the classroom. By contrast, in the KGU documents the local environs were referenced infrequently, but 'Japan' was mentioned 26 times and the word for 'nation' or 'country' (kuni) was mentioned 21 times. Six of these occurrences referred to 'developing countries', and 6 made reference to the expression rainichi, or 'returning to Japan'. The keyword 'international' also made a strong 
showing in comparison to the UK case, with 66 (1.4\%) mentions to UCL's 10 (.1\%). The focus on Japan, nation and international and the President's emphasis on students learning what it means to be Japanese signifies a view of the world in which nation-states are key actors, and lends support to arguments that internationalisation efforts in Japan are typically imbued with "a desire to protect and promote Japanese national identity" (Burgess, 2010).

Both universities made reference to themselves in the documents, although UCL was by far more selfreferential. UCL seemed to make a concerted effort to highlight the University's brand name with 121 mentions (1.2\%); the only keyword that showed up more frequently was the word 'global' (161 mentions, $1.6 \%)$. By contrast, KGU referred to itself considerably less often with only 18 mentions (0.38\%), although it made a point to highlight the university's connections with the United Nations, with 64 mentions of the organisation.

\section{Are the GCE programmes focused on producing global workers rather than global citizens?}

A theme that was dominants throughout both cases was a discourse of employability. In the case of UCL, the high frequency of terms like career, employer, professional skills, and networking can be explained in part because there is an entire Global Citizenship Pathway devoted to the theme of Employability, and many of these terms showed up on the webpage describing this pathway (UCL webpage E, n.d.). Although the connection of this strand to academic and advocacy-type conceptions of global citizenship is tenuous, the pathway appears to be a recurring option for students since 2014. The theme of employability is also clearly articulated in the KGU programme. The first step of the programme involves challenging students to envision their future 'global career', and embarking on the appropriate pathway to achieve this goal (KGU webpage G, n.d.). From there, students can select modules and internships that will give them the skills needed to succeed in the future, becoming one of Japan's 'global human resources'.

A second, and perhaps connected, theme was the emphasis in both cases on the development of practical skills and abilities. Teamwork ability, cross-cultural awareness, and leadership skills are highlighted throughout the descriptions of both the UCL and KGU programmes. As was mentioned above, the KGU programme also puts a strong emphasis on language skills, especially English. Many of these traits align with the ideal Global Worker model that informed the analytical framework used for this study, although most tend to fall in the category of characteristics where there is an overlap of the concepts of global workers and global citizens. Thus, with regard to skills development, there was ample evidence in both cases highlighting how in practice, the cultivation of global citizens is markedly intertwined with the production of global workers.

\section{Discussion and Conclusions}


Our analysis shows that GCE programmes in the UK and Japanese contexts, while different in a number of respects, exhibited some noteworthy similarities. Both programmes had infused within them an agenda of employability, pointing to the potential co-optation of global citizenship discourse by neoliberal objectives aimed at the production of globally competent workers. In the case of Japan, the production of these global workers connected to the broader goal of helping the Japanese nation compete in the global knowledge economy, tying notions of global citizenship to conceptions of ethnic national identity. The UK case emphasized instead a localized, heavily branded and marketized approach to programme promotion, an approach consistent with the demands placed on HEIs to maintain global competitiveness.

Comparing GCE programmes in contrasting contexts highlighted the range of possibilities for GC to be conceptualized in practice in higher education. This variation can be explained in part because there were a number of instances in both cases where the GCE programme contents were connected to broader university strategies. In the case of UCL, a major component of the GCE programme is linked to the University's strategic vison of addressing its 'Grand Challenges', the 4 (at the time, and now 6) global 'problems' that UCL has committed to helping solve through cross-disciplinary collaboration. In the case of KGU, the GCE programme clearly fits within its broader internationalization strategy and connects directly to government internationalization initiatives, and the fact that the national government has recognised the value of this strategy by awarding funding to the university is noted on a number of occasions in its GCE documents.

Contrasting GCE programming at institutions in a non-Western and archetypically Western context highlighted a number of examples of adaptation and localization of GCE to both institutional - and in the case of Japan - national, priorities. The nationalistic emphasis found in the KGU case is indicative of a broader pattern of how citizenship has traditionally been conceptualized in Japanese formal education. Citizenship education was virtually non-existent in Japan until it was imposed by the Americans during the Occupation after World War II (Willis, 2002). Prior to this time, the Japanese were educated to be shinmin, or loyal subjects, as opposed to shimin ('citizens'). Since the time of the Meiji Restoration, developing shinmin has gone hand in hand with the inculcation of nationalist identities (ibid.), with the dominant model still found in policy rhetoric being a form of ethnic nationalism (Doak, 1996, 1997). As a result, ideas about citizenship in Japan tend to be bound up with notions of ethnic identity (Willis, 2002). The message of KGU's President encouraging the University's 'world citizens' to develop a sense of Japanese identity through interactions with foreign cultures aligns with this view, and with critiques of Japanese approaches to internationalisation being focused on reinforcing "the idea of Japanese as being different from all other people and for that difference to be properly understood outside Japan” (Goodman, 2007, p. 72). 
While a nationalistic orientation was absent in the UCL GCE programme documents, the emphasis was instead placed on UCL's own brand and the important role of the University and its global graduates can play in addressing what it considers to be today's global problems. The high frequency of university branding infused throughout the programme documents points to UCL's commercialized and marketingoriented approach to its public-facing web presence. Even though UCL is a top-ranked research institution in the developed English-speaking world and can attract fee-paying enrollees with relative ease, the GCE programme is, at times, pitched to student-consumers as a bonus add-on to their degree that will help them 'expand their network, get ready for their career, and improve their CVs' (UCL webpage R).

As noted above, increased global competitiveness coupled with the expansion of higher education participation worldwide have led many universities to intensify efforts at enhancing the employability of their graduates. Within this environment, it is perhaps understandable that we encountered the employability agenda incorporated into university-wide extracurricular initiatives. The fact that employability has presented itself in the GCE programmes in both cases is arguably a sign of the widespread corporatization and co-optation of higher education by a neoliberal agenda. However, this is not the only possible interpretation or indeed, the only reason for employability to be linked to GCE. In contrast to universities in the West, Japanese HE has since its inception been geared towards the development of human capital and national competitiveness (Nakayama, 1989), and so infusing elements of manpower planning and employability into curricula could be interpreted as being in keeping with traditional practice. Furthermore, the small-scale approach to both case selection and methodology in this study mean that our findings should be considered exploratory rather than generalizable. That said, the ubiquity of the employability agenda, both within each institution and across the distinct institutional contexts, does align with the broader neoliberal trends shaping the global higher education landscape. The two programmes conceptualise GC in different ways and emphasise the value of different skills, but each also clearly utilizes the rhetoric of GC to foster the development of globally competent workers. The variation in programme design corresponds to the fact that each university recognizes its position in the global higher education landscape and alters its policy and programming accordingly, with each having the shared goal of augmenting their institution's global competitiveness.

While it may be useful for universities to infuse employability into their teaching and learning strategies and extra-curricular offerings, there is a risk that this trend could dilute the civic meanings and purposes that were supposed to be their foundational rationale. At this juncture, the two programmes we have examined here suggest that GCE do not just (or even primarily) focus on creating global workers; they also provide a space for the development of globally-aware, empathetic and engaged citizens. The increasing prevalence of GCE programmes at universities may therefore contribute to the preservation of higher 
education as a safe place for critical civic engagement advocated for by Giroux (2002). However, as the marketization of higher education continues to intensify, the challenge for educators, students and policymakers will be to ensure that employability and neoliberal agendas do not come to dominate GCE programmes, and that these programme remain spaces for critical civic engagement and for fostering mutual understanding and peaceful relations in a globalizing world.

\section{Bibliography}

Altbach, P. G., \& Knight, J. (2007). The Internationalization of Higher Education: Motivations and Realities. Journal of Studies in International Education, 11(3-4), 290-305. http://doi.org/10.1177/1028315307303542

Brooks, R., \& Waters, J. (2013). Global Graduates, Student Mobility and the Funding of Higher Education. In Student Financing of Higher Education: a Comparative Perspective (pp. 137-154). London and New York: Taylor \& Francis.

Brown, P., Lauder, H., \& Ashton, D. (2011). The global auction: The broken promises of education, jobs, and incomes. Oxford: Oxford University Press.

Burgess, C. (2010). Higher education: Opening up or closing in? Contradictory reform goals could scotch chances of success. Retrieved August 17, 2015, from http://www.japantimes.co.jp/community/2010/03/23/issues/higher-education-opening-up-or-closingin/\#.VdHQnXihifQ

Diamond, A., Walkley, L., Forbes, P., Hughes, T.,Sheen, J. (2008). Global Graduates into Global Leaders. Vasa.

Doak, K. M. (1996). Ethnic nationalism and romanticism in the early twentieth-century Japan. Journal of Japanese Studies, 22(1), 77-103.

Doak, K. M. (1997). What is a nation and who belongs? National narratives and the ethnic imagination in twentieth-century Japan. The American Historical Review, 102(2), 283-309.

Dower, N. (2003). An Introduction to Global Citizenship. Edinburgh: Edinburgh University Press.

Fujikane, H. (2003). Approaches to Global Education in the United States, the United Kingdom and Japan. International Review of Education, 49(1/2), 133-152. http://doi.org/10.2307/3445478

George-Jackson, C. E. (2010). The Cosmopolitan University: The medium toward global citizenship and justice. Policy Futures in Education, 8(2), 191-200. http://doi.org/10.2304/pfie.2010.8.2.191

Giroux, H. A. (2002). Neoliberalism, corporate culture, and the promise of higher education: the university as a democratic public sphere. Harvard Educational Review, 72(4), 425-463. http://doi.org/http://dx.doi.org/10.17763/haer.72.4.0515nr62324n71p1

Goodman, R. (2007). The concept of kokusaika and Japanese educational reform. Globalisation, Societies 
and Education, 5(1), 71-87.

Graddol, D. (2000). The Future of English: A guide to forecasting the popularity of the English language the 21st century. The British Council.

Haigh, M. (2008). Internationalisation, planetary citizenship and Higher Education Inc. Compare: A Journal of Comparative and International Education, 38(4), 427-440. http://doi.org/10.1080/03057920701582731

Huang, F. (2007). Internationalisation of Higher Education in the Era of Globalisation: What have been its Implications in China and Japan? Higher Education Management and Policy, 19(1), 1-15. http://doi.org/10.1787/hemp-v19-art3-en

Jorgenson, S., \& Shultz, L. (2012). Global Citizenship Education (GCE) in Post-Secondary Institutions: What is Protected and what is Hidden under the Umbrella of GCE? Journal of Global Citizenship \& Equity Education, 2(1), 1-22.

Keating, A. (2014). Education for Citizenship in Europe: European Policies, National Adaptations and Young People's Attitudes (1st ed.). Palgrave Macmillan UK.

Keating, A., Ortloff, D. H., \& Philippou, S. (2009). Citizenship education curricula: the changes and challenges presented by global and European integration. Journal of Curriculum Studies, 41(2), 145-158. http://doi.org/10.1080/00220270802485063

Larner, W. (2000). Neo-Liberalism: Policy, Ideology, Governmentality. Studies in Political Economy, 63, 5-25. http://doi.org/10.1016/j.geoforum.2009.03.010

Lewin, R. (2009). Introduction: The Quest for Global Citizenship through Study Abroad. In R. Lewin (Ed.), The Handbook of Practice and Research in Study Abroad: Higher Education and the Quest for Global Citizenship (pp. xiii-xxii). New York: Routledge.

Lynch, K. (2006). Neo-liberalism and Marketisation: the implications for higher education. European Educational Research Journal, 5(1), 1. http://doi.org/10.2304/eerj.2006.5.1.1

Marginson, S. (2011). Higher education in East Asia and Singapore: the rise of the Confucian Model. Higher Education, 61(5), 587-611. http://doi.org/10.1007/s

Marginson, S. (2014). Higher Education as a Public Good in a Marketized East Asian Environment. In A. Yonezawa, Y. Kitamura, A. Meerman, \& K. Kuroda (Eds.), Emerging International Dimensions in East Asian Higher Education (pp. 15-33). Dordrecht: Springer.

Marginson, S., \& van der Wende, M. (2007). Globalisation and Higher Education. OECD Education Working Papers, No. 8. OECD Publishing (NJ1).

Marshall, H. (2009). Educating the European citizen in the global age: engaging with the post-national and identifying a research agenda. Journal of Curriculum Studies, 41(2), 247-267. http://doi.org/10.1080/00220270802642002

McCullough, D. (2008). Moral and social education in Japanese schools: Conflicting conceptions of citizenship. International Journal of Citizenship and Teacher Education, 4(1).

MEXT. (n.d.). Project for Promotion of Global Human Resources. Retrieved February 25, 2017, from http://www.mext.go.jp/en/policy/education/highered/title02/detail02/sdetail02/1373895.htm

MEXT. (2014). Selection for the FY 2014 Top Global University Project. Retrieved November 17, 2015, from http://www.mext.go.jp/b_menu/houdou/26/09/_icsFiles/afieldfile/2014/10/07/1352218_02.pdf 
Mitchell, K. (2003). Educating the national citizens in neoliberal times: from the multicultural self to the strategic cosmopolitan. Transactions of the Institute of British Geographers, 28(4), 387-403.

Mok, K.-H. (2007). Questing for internationalization of universities in Asia: Critical reflections. Journal of Studies in International Education, 11(3-4), 433-454. http://doi.org/10.1177/1028315306291945

Naidoo, R., \& Jamieson, I. (2005). Knowledge in the marketplace: the global commodification of teaching and learning in higher education. Internationalizing Higher Education: Critical Explorations of Pedagogy and Policy, 37-51. http://doi.org/10.1007/1-4020-3784-8_3

Nakayama, S. (1989). Independence and choice: Western impacts on Japanese higher education. In P. G. Altbach \& V. Selvaratnam (Eds.), From Dependence to Autonomy: The Development of Asian Universities (pp. 97-114). Dordrecht: Kluwer Academic Publishers.

Nussbaum, M. (2002). Education for citizenship in an era of global connection. Studies in Philosophy and Education, 21, 289-303. http://doi.org/10.1023/A:1019837105053

Oxfam. (2015). Education for Global Citizenship. Retrieved March 12, 2017, from http://www.oxfam.org.uk/education/global-citizenship/global-citizenship-guides

Oxley, L., \& Morris, P. (2013). Global citizenship: A typology for distinguishing its multiple conceptions. British Journal of Educational Studies, 61(3), 301-325. http://doi.org/10.1080/00071005.2013.798393

Pashby, K. (2011). Questions for Global Citizenship Education in the Context of the "New Imperialism" For Whom? By Whom? In V. Andreotti \& L. de Souza (Eds.), Postcolonial Perspectives on Global Citizenship Education. London: Routledge.

Rhoads, R. A., \& Szelenyi, K. (2011). Global Citizenship and the University: Advancing Social Life and Relations in an Interdependent World. Stanford: Stanford University Press.

Schattle, H. (2009). Global Citizenship in Theory and Practice. In R. Lewin (Ed.), The Handbook of Practice and Research in Study Abroad: Higher Education and the Quest for Global Citizenship (pp. 3-20). New York: Routledge.

Schweisfurth, Michele (University of Birmingham, U. (2006). Education for global citizenship: teacher agency and curricular structure in Ontario schools. Educational Review, 58(1), 41-50. http://doi.org/10.1080/00131910500352648

Scott, J. (1990). A Matter of Record: Documentary Sources in Social Research. Cambridge: Polity Press.

Tsuneyoshi, R. (2011). The "internationalization" of Japanese education and the newcomers: Uncovering the paradoxes. In D. B. Willis \& J. Rappleye (Eds.), Reimagining Japanese Education: borders, transfers, circulations, and the comparative. Oxford: Symposium.

Willis, D. B. (2002). Citizenship Challenges for Japanese Education for the 21st Century: "Pure" or "Multicultural"? Multicultural Citizenship Education in Japan. International Education Journal, 3(5), 33-49.

Yonezawa, A. (2014). Japan's challenge of fostering "global human resources": Policy debates and practices. Japan Labor Review, 11(2), 37-52.

\section{Appendix A: List of Documentary Data Sources}




\section{KGU websites (Data collected between April 2, 2016 and February 10, 2017)}

A. Gakucho messeji [President's Message]. Retrieved April 02, 2016, from Kwansei Gakuin Daigaku jissengata "sekai shimin" ikusei puroguramu [Kwansei Gakuin University's programme model for cultivating "World Citizens"]: http://kgglobal.kwansei.ac.jp/purpose/purpose_005994.html

B. sekai shimin to gurobaru jinzai to wa [defining world citizens and global human resources]. Retrieved April 02, 2016, from Kwansei Gakuin Daigaku jissengata "sekai shimin" ikusei puroguramu [Kwansei Gakuin University's programme model for cultivating "World Citizens"]: http://kgglobal.kwansei.ac.jp/purpose/purpose_005992.html

C. minitsuku chikara [aquiring power]. Retrieved April 02, 2016, from Kwansei Gakuin Daigaku jissengata "sekai shimin" ikusei puroguramu [Kwansei Gakuin University's programme model for cultivating "World Citizens"]: http://kgglobal.kwansei.ac.jp/purpose/purpose_006051.html

D. kore made no jisseki [achievements up until now]. Retrieved April 02, 2016, from Kwansei Gakuin Daigaku jissengata "sekai shimin" ikusei puroguramu [Kwansei Gakuin University's programme model for cultivating "World Citizens"]: http://kgglobal.kwansei.ac.jp/purpose/purpose_005996.html

E. Kokuren to no renkei [Cooperation with the United Nations]. Retrieved April 02, 2016, from Kwansei Gakuin Daigaku jissengata "sekai shimin" ikusei puroguramu [Kwansei Gakuin University's programme model for cultivating "World Citizens"]: http://kgglobal.kwansei.ac.jp/purpose/purpose_005997.html

F. karikyuramu [curriculum]. Retrieved April 02, 2016, from Kwansei Gakuin Daigaku jissengata "sekai shimin" ikusei puroguramu [Kwansei Gakuin University's programme model for cultivating "World Citizens"]: http://kgglobal.kwansei.ac.jp/purpose/purpose_005997.html

G. puroguramu no nagare [course of programme]. Retrieved April 02, 2016, from Kwansei Gakuin Daigaku jissengata "sekai shimin" ikusei puroguramu [Kwansei Gakuin University's programme model for cultivating "World Citizens"]: http://kgglobal.kwansei.ac.jp/programs/programs_006009.html

H. kaku koosu shoukai [introducing each course]. Retrieved April 02, 2016, from Kwansei Gakuin Daigaku jissengata "sekai shimin" ikusei puroguramu [Kwansei Gakuin University's programme model for cultivating "World Citizens"]: http://kgglobal.kwansei.ac.jp/programs/programs_006013.html

I. kamoku shoukai [subject introduction]. Retrieved April 02, 2016, from Kwansei Gakuin Daigaku jissengata "sekai shimin" ikusei puroguramu [Kwansei Gakuin University's programme model for cultivating "World Citizens"]: http://kgglobal.kwansei.ac.jp/programs/programs_006018.html

J. shinrou ni tsuite [regarding university choices]. Retrieved April 02, 2016, from Kwansei Gakuin Daigaku jissengata "sekai shimin" ikusei puroguramu [Kwansei Gakuin University's programme model for cultivating "World Citizens"]: http://kgglobal.kwansei.ac.jp/programs/programs_006027.html

K. gurobaru shitizen coosu shūryō tan'i-hyō [global citizen course credit completion table]. Retrieved February 10, 2017, from Kwansei Gakuin Daigaku jissengata "sekai shimin" ikusei 
puroguramu [Kwansei Gakuin University's programme model for cultivating "World Citizens"]: http://kgglobal.kwansei.ac.jp/attached/0000090313.pdf

\section{UCL websites included in the analysis (Data collected between March 14, 2016 and February 26, 2017)}

Arthur, M. (2015, February 20). Provost's Perspective: Becomming a Global Citizen. Retrieved March 14, 2016, from UCL News: http://www.ucl.ac.uk/news/students/022015/022015-20022015provosts-perspective

A. UCL Global Citizenship Programme. Retrieved April 2, 2016, from UCL Global Citizenship: http://www.ucl.ac.uk/global-citizenship/programme

B. UCL Grand Challenges courses. Retrieved April 02, 2016, from Global Citizenship: http://www.ucl.ac.uk/global-citizenship/programme/grand-challenges

C. Enterprise - overview. Retrieved April 02, 2016, from UCL Enterprise: http://www.ucl.ac.uk/global-citizenship/programme/pathways/enterprise

D. Voluntary Sector. Retrieved April 02, 2016, from Global Citizenship: http://www.ucl.ac.uk/global-citizenship/programme/pathways/voluntary-sector

E. Employability. Retrieved April 02, 2016, from Global Citizenship: http://www.ucl.ac.uk/globalcitizenship/programme/pathways/employability

F. Active Citizenship. Retrieved April 02, 2016, from Global Citizenship: http://www.ucl.ac.uk/global-citizenship/programme/pathways/active-citizenship

G. UCL Global Citizenship. Retrieved April 02, 2016, from UCL Global Citizenship: http://www.ucl.ac.uk/global-citizenship

H. The Danube (Intercultural Interaction). Retrieved April 02, 2016, from Global Citizenship: http://www.ucl.ac.uk/global-citizenship/programme/grand-challenges/the-danube

I. Global Alliances for Local Change (Sustainable Cities). Retrieved April 02, 2016, from Global Citizenship: http://www.ucl.ac.uk/global-citizenship/programme/grand-challenges/globalalliances

J. Health in Future Cities (Global Health). Retrieved April 02, 2016, from Global Citizenship: http://www.ucl.ac.uk/global-citizenship/programme/grand-challenges/health-future-cities

K. (Un)Urban: Investigating Green Spaces in East London (Human Wellbeing). Retrieved April 02, 2016, from Global Citizenship: http://www.ucl.ac.uk/global-citizenship/programme/grandchallenges/global-prosperity

L. Global Environmental Justice (Sustainable Cities). Retrieved April 02, 2016, from Global Citizenship: http://www.ucl.ac.uk/global-citizenship/programme/grandchallenges/environmental-justice

M. Outbreak! Infectious Diseased and Global Citizenship from the Plague to Ebola (Global Health). Retrieved April 02, 2016, from Global Citizenship: http://www.ucl.ac.uk/globalcitizenship/programme/grand-challenges/outbreak 
N. Pathways strands. Retrieved April 02, 2016, from Global Citizenship: http://www.ucl.ac.uk/global-citizenship/programme/pathways

O. Key Benefits. Retrieved April 02, 2016, from Global Citizenship: http://www.ucl.ac.uk/globalcitizenship/programme/key-benefits

P. What is a Global Citizen? Retrieved April 02, 2016, from Global Citizenship: http://www.ucl.ac.uk/global-citizenship/programme/what-is-a-global-citizen

Q. UCL Global Citiizenship Programme: Information for UCL staff. Retrieved April 02, 2016, from Global Citizenship: http://www.ucl.ac.uk/global-citizenship/programme/staff-information

R. 'Integration of research and education", accessed 25 February 2017 https://www.ucl.ac.uk/2034/themes/integrating-research-education

S. '5 things...to know about UCL Global Citizenship, accessed 26 February, 2017: https://www.ucl.ac.uk/teaching-learning/news/may/2015/5-things...-know-about-ucl-globalcitizenship 